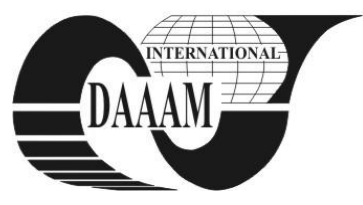

Annals of DAAAM for 2011 \& Proceedings of the 22nd International DAAAM Symposium, Volume 22, No. 1, ISSN 1726-9679 ISBN 978-3-901509-83-4, Editor B. Katalinic, Published by DAAAM International, Vienna, Austria, EU, 2011 Make Harmony between Technology and Nature, and Your Mind will Fly Free as a Bird Annals \& Proceedings of DAAAM International 2011

\title{
EQUIPMENT FOR MATERIAL TESTING AND ADVANCED CHARACTERIZATION
}

\section{GUTT, S[onia]; GUTT, G[heorghe]; SEVERIN, T[raian] - L[ucian]; MIRONEASA, S[ilvia]; POROCH - SERITAN, M[aria] \& ALEXUC, F[lorin] - C[ristian]}

\begin{abstract}
The paper refers to electronic laboratory equipment meant to material hardness testing as well as to other important material characteristics such as: modulus, work of elastic deformation, work of plastic deformation, creep tendency. With that end in view we used a force sensor to measure the force applied to indenter, a mechanical system for the cycle of loading and unloading and an electronic system to calculate the depth of penetration The equipment consists of an electromechanical loading and unloading system, made by a cam shaft, which runs a constant and known path for indenter, at full rotation of the shaft. As a result of graphic registration of pairs of values: force F) - depth of penetration d) during the loading-unloading cycle, a specific curve is obtained to determine the mentioned characteristic sizes of material. The equipment is of portable and modular type, under laboratory conditions is mounted on a tripod whereas under factory working conditions on the working head of machine tools.

Key words: hardness, depth, penetration, loading-unloading cycle
\end{abstract}

\section{INTRODUCTION}

Presently, to characterize materials in terms of their behaviour when trying to penetrate them by an indenter with a given geometry and much harder than these ones, the mechanical hardness testing is used, which from the instrumental point of view is widely varied as it covers an important area of hardness values and a variety of materials as well, from metals to plastics and composite materials. Thus, to determine hardness of metals with static loads, a number of methods such as Vickers, Weiler W., 1990) Brinell, Rockwell, Knoop, Berkovich, etc, (Czichos H., et al., 2006), (Gutt G. et al., 2000, 2010, 2010-1)),(Weiler W., et al., 1990),(Gutt S. et al., 2011-1), and hardness of plastics, methods such as Shore IRHD, Barco, etc. (ASTM-D-2240) are known. As regards the former ones, the hardness of metals is expressed as ratio between the load applied to identer and its trace surface area left on the tested material after removing the load, using the plastic deformation component of the material tested to calculate its hardness; for the latter ones, the hardness of plastics is expressed by the penetration depth of indenter in the tested material without removing the load (DIN EN ISO 14.577), (Amsstrong 2005), using both the elastic deformation component and the plastic one.

\section{EXPERIMENTAL}

The equipment for material testing and advanced characterization presented in the paper is an electronic device that allows to determine the hardness of the material tested and other characteristic physical sizes using a cyclic system of loading-unloading with constant and known displacement of indenter. A curve fig. 2), passing through the pairs of values Force-F, displacement-d, results from carrying out the loadingunloading cycle.

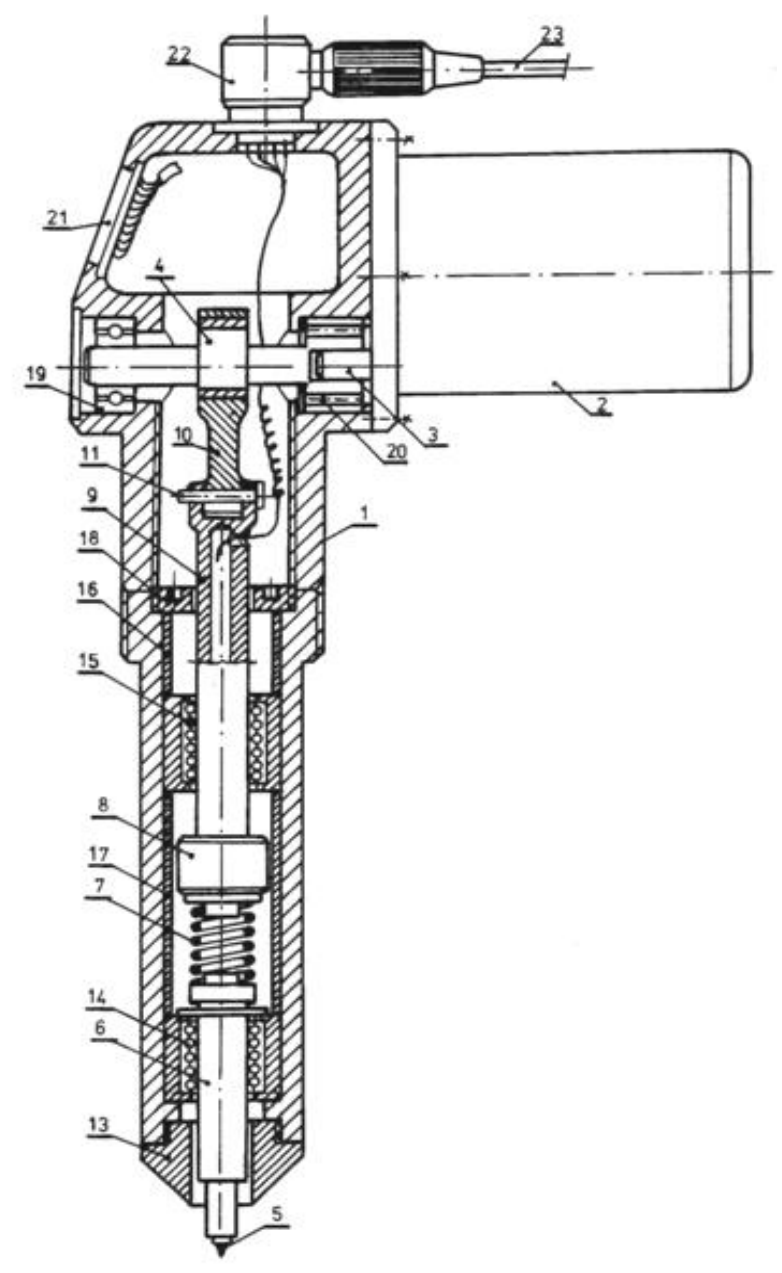

Fig.1. Loading and unloading equipment structure within the material testing and advanced characterization device. 1-body, 2-electric control motor, 3-shaft, 4-eccentric shaft, 5-penetrator, 6-portpenetrator, 7-compression spring, 8-dynamometric cell, 9-cylindrical rod, 10-connecting rod, 11-bolt, 12-material tested, 13-limiting body, 14,15-ball bushes, 16,17-spacing rings, 18- coupling nut, 19-ball bearing, 20-needle bearing, 21alpha-numerical display, 22-electric connector, 23-electric cable.

The force being measured by a force sensor of dynamometric electronic cell type, 8 Fig.1), and displacement being determined from the microprocessor computing device by the product between the value of shaft eccentricity double and that of time read simultaneously with the force one. Loading and unloading equipment structure shown under laboratory testing conditions is fixed on a tripod, and under plant working conditions it is attached to the working head of 
machine tools, the approaching and positioning of the material tested being made by their system of coordinate displacement.

\section{RESULTS AND DISCUSSION}

Principles to determine the quantities of material characteristics using the described device are the following:

$$
H=K \cdot F_{\max }
$$

Determination of hardness $H$ is achieved by an automatic electronic extrapolation of the maximum force value $F_{\max }$ on a calibration curve carried out in coordinates: loading force- $F_{i}$, hardness $H$, by determining the values of force $F_{i}$ corresponding to some precise hardness values provided by standard hardness plates: In its turn, the maximum force Fmax is automatically calculated when the first derivative tangent angle $\alpha$, Fig. 2) of unloading force versus time $t$ is zero:

$$
F_{\max } \rightarrow \frac{d F}{d t}=0
$$

Determination of modulus of elasticity $E$ is made by automatic electronic extrapolating of the tangent value of angle $\alpha$, determined from the slope of the unloading force $F_{d}$, Fig. 1):

$$
\frac{1}{E} \approx \frac{\Delta F_{d}}{\Delta t}=\operatorname{tg} \alpha
$$

on a calibration curve carried out in discharge Force $F_{d}$ Modulus of elasticity $E$ coordinates, the different values of modulus of elasticity needed for the standard curve being provided by standard plates with precise values of the modulus of elasticity.

Determination of mechanical work $W_{e l}$ of elastic deformation is made by correlating it with the surface integral $S_{i}$ of the loading curve:

$$
W_{e l} \approx \int S_{i}
$$

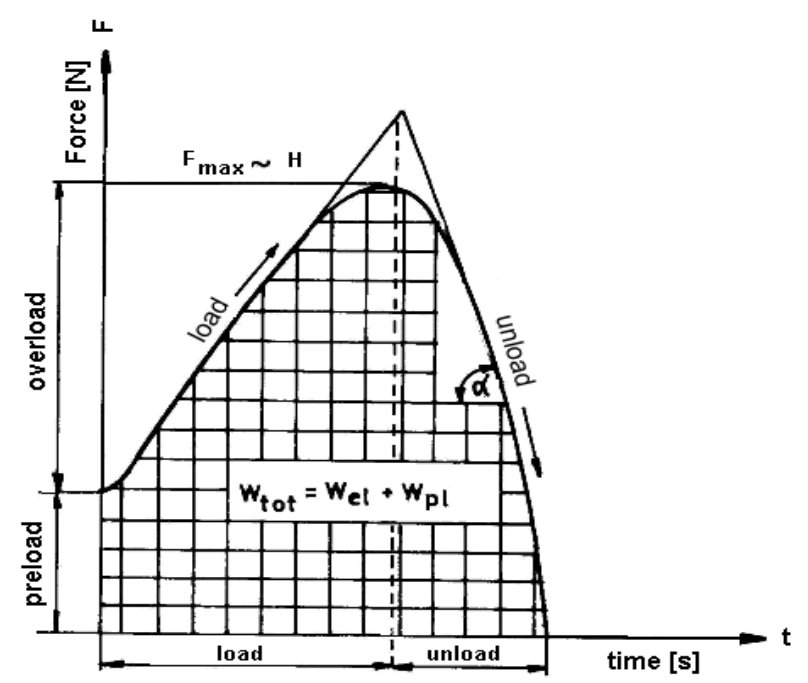

Fig.2 Specific loading-unloading curve achieved by the automatic recording of force $F$ versus time $t$, curve used in determining modulus of elasticity $E$, work of elastic deformation $W_{e l}$, work of plastic deformation $W_{p l}$, total work of deformation $W_{t o t}$ for the material tested
Determination of mechanical work $W_{P L}$ of plastic deformation is made by correlating it with the surface integral $S_{d}$ of the unloading curve:

$$
W_{p l} \approx \int S_{d}
$$

Determination of mechanical work $W_{t o t}$ of total deformation is made by correlating it with the sum between the surface integral value $S_{i}$ of the loading curve and surface integral value $S_{d}$ of the unloading curve:

$$
W_{t o t} \approx W_{e l}+W_{p l} \approx \int S_{i}+\int S_{d}
$$

$T_{f}$ creep tendency of the tested material is given by the tangent slope to evolution of maximum load $F_{\max }$ during $t_{l}$ time:

$$
T_{f}=\frac{\Delta F_{\max }}{\Delta t_{1}}=\operatorname{tg} \gamma
$$

after the engine of loading system has been automatically stopped when reaching the maximum load value provided by zero value of $F$ force first derivative depending on time $t$.

\section{CONCLUSIONS}

The advantages of the equipment presented regarding the material advanced characterization bring about new ways of determining hardness and some characteristic quantities of material using a single force sensor, which leads to maximum design simplicity and low cost price of equipment. The uncertainty in determining zero penetration depth of indenter, specific to classical hardness tests, including Martens hardness, is eliminated as well. The equipment described is of portable and modular type and allows testing to be made both under laboratory and factory conditions.

\section{REFERENCES}

Czichos H., Saito T.,Smith L., 2006). Handbook of Material Measurements Methods, Springer Verlag Berlin, p. 311-333

Weiler W., Leeb D.H., Müller K., Rupp D.,M., 1990)Härteprüfung, an Metallen und Kunsststoffen , 2. Auflage, Experverlag Ehningen bei Böblingen, p.60-100

Amstrong R., Ferranti L., jr., Thadhani N. N., 2005), Elastic/plastic/cracking indentation behavior of hard materials,International Journal of Refractory Metals \& Hard Materials 24, p. 11-16

DIN EN ISO 14.577 - Instrumentierte Eindringprüfung, ASTM - D-2240

Gutt S., Gutt G., Severin T., L., Gutt A., 2010-1) Apparatus for material testing and advanced characterization, Romanian), Patent proposals OSIM Bucuresti, A00/873/2010.

Severin, T, Gutt, S, Poroch - Seritan, M., Gutt,G, Gutt S., Stroe, S.,G., 2010-1). Study the technological parameters influence on the hardness ofaNi-W alloys obtained by galvanic deposition , Annals of DAAAM for 2010 \& Procedings of the 21st International DAAM Symposium, Viena 2010, p. 1011-1013

Gutt G., Gutt S., 2000) Testing and characterization of metallic materials, Romanian), Editura Tehnica Bucuresti, p. 204 311

Gutt, S.,Gutt, G., Severin, T.,L., Poroch - Seritan, M., Mironeasa S., Oroian M., M-Portable Hardness Tester, DAAM 2011 